\title{
Bolsonaro e a COVID-19: e daí? "o Brazil tá matando o Brasil”, “do Brasil, SOS ao Brasil", "chora a nossa pátria, mãe gentil..."
}

Caía a tarde feito um viaduto, e um bêbado, trajando luto, me lembrou Carlitos. A lua, tal qual a dona do bordel, pedia a cada estrela fria um brilho de aluguel. E nuvens, lá no mata-borrão do céu, chupavam manchas torturadas. Que sufoco! Louco! O bêbado, com chapéu-coco, fazia irreverências mil pra noite do Brasil. Meu Brasil! Que sonha com a volta do irmão do Henfil, com tanta gente que partiu num rabo de foguete.

Chora nossa Pátria, mãe gentil, choram Marias e Clarisses no solo do Brasil. Mas sei que uma dor assim pungente não há de ser inutilmente. A esperança dança na corda bamba de sombrinha e, em cada passo dessa linha, pode se machucar.

Azar! A esperança, equilibrista, sabe que o show de todo artista tem que continuar.

Meu Brasil

(Aldir Blanc e João Bosco - O bêbado e a equilibrista)

\section{Começando com política, música, poesia...}

Devido a esses tempos de pandemia e pandemônio, tempos tão difíceis, perigosos e duros, de crise e contradições na economia política do capital, de crise sanitária, causada pela Covid-19, começamos este editorial enfatizando a relação dialética entre arte e política e homenageando três artistas que lutaram por uma cultura emancipatória e crítica, falecidos no mês de maio, nomeadamente Aldir Blanc, Moraes Moreira e Rubem Fonseca, além de Flávio Migliaccio, cuja carta de despedida nos deu elementos para pensar a velhice-estorvo no capitalismo, antes e durante esta pandemia. Todos eles serão homenageados nestas páginas. Daremos voz aos três, mas nos concentraremos na obra genial de Aldir Blanc, essencialmente em seus mais belos hinos de protesto, denúncia e resistência: O bêbado e a equilibrista e Querelas do Brasil. O primeiro refere-se à Anistia, ou seja, àqueles que "partiram num rabo de foguete" durante os sombrios anos de chumbo e voltaram do exílio forçado pelo mundo afora. E o segundo nos faz refletir sobre a situação do Brasil atual e a questão da soberania nacional. A atualidade dessas duas canções nos estimula a pensar nestes tempos sombrios sob o governo protofascista de Bolsonaro, que, cercado de empresários e políticos corruptos, militares irresponsáveis e dezenas de milicianos fanáticos, rememora alguns episódios deploráveis e violentos da ditadura de 1964. Estas músicas nos remetem ao passado e à atualidade, onde o protofascismo veio fazer morada, tanto antes quanto durante a pandemia da Covid-19. As querelas a que música alude significam conflitos, queixas-crime e divergências, conforme o Aurélio, estão explícitas, pretendem denunciar a forma violenta com que se revestem as palavras, as ações e os métodos do antipresidente, sem o mínimo de decoro que o cargo exige, civilidade, e outros atributos inerentes à sua verve 
autoritária e fascista. Tudo parece um grande pesadelo, que muito se assemelha ao estágio rudimentar, inicial ou primitivo do fascismo engendrado na Itália por Benito Mussolini.

Portanto, conforme o conteúdo das referidas músicas, fica claro que estamos num sistema político que bebe das águas turvas e funestas do fascismo, do despotismo, da violência, da censura, das 'cirandas da morte' (milicianos), do armamento da sociedade, enfim, da morte do Estado de Direito e do advento do Estado de Exceção, que emergiram mais claramente a partir das eleições de 2018 e permanecem até os dias atuais. Bolsonaro, em suas distopias malévolas e narrativas beligerantes e mórbidas, vem mantendo um governo antidemocrático e autoritário, ou ditatorial, ${ }^{1}$ cujas lógica e prática são irmãs siamesas do Estado Policial, ${ }^{2}$ de caráter miliciano, mas que tem ramificações na própria polícia, fora dela e nas Forças Armadas. O que se intui, nas letras de Aldir, é que todas as imagens que aparecem nos versos mostram as contradições da defesa da vida com a prática e a 'política da morte'. Esse tipo de política vem sendo uma constante no que tange à criminalização dos movimentos populares, sociais e sindicais, haja vista as mortes de militantes e políticos de esquerda (Marielle Franco), de indígenas, de trabalhadores negros e de defensores das causas ambientais.

Todo esse emaranhado de barbáries do presente nos remete indubitavelmente a "um tempo, página infeliz da nossa história, passagem desbotada na memória das nossas novas gerações", enquanto "dormia a nossa pátria, mãe tão distraída, sem perceber que era subtraída em tenebrosas transações". 3

Aldir Blanc já foi evocado em outros editorias. Sua última aparição nestas paragens deu-se por meio de sua metáfora da "esperança equilibrista", inspiração da capa da edição final de Motrivivência $^{4}$ em 2018, esperança esta que tem sido nosso esteio, verdadeiro incentivo à resistência ativa em prol de um projeto emancipatório de democracia. Suas músicas são um libelo em favor de uma formação política anticapitalista e antifascista. São palavras de alerta que marcam indelevelmente a nossa memória. Versos que sangram e nos levam a chorar de indignação e advertência em meio à luta firme e determinada contra os tempos obscurantistas atuais. As músicas $O$ bêbado e a equilibrista e Querelas do Brasil nos brindam com versos de indignação e resistência repletos de "esperança equilibrista", em cujas linhas se denuncia: "O Brazil está matando o Brasil", "Do Brasil, SOS ao Brasil". As duas obras são verdadeiros documentos-testemunhos da realidade, flechas poético-políticas contra os fantasma da ditadura militar, que, hoje, teimam em retornar, mancomunados com as milícias bolsonaristas, forjadas no limiar do Estado Policial e das Forças Armadas, que estão expressamente no comando, com toda força, do leme do poder. Esta gente infeliz, o rebanho bolsonarista, que se autointitula 'intervencionista', sinônimo de protofascista, conspira em frente ao planalto; possivelmente aquartelada nos porões da caserna, anuncia claramente as garras do sanguinário Estado de Exceção. Os versos de Aldir Blanc não conseguem, no entanto, sensibilizar uma parcela de 25 a 30\% da sociedade brasileira que votou no Bozo. Por essa razão, eles negam a existência da ditadura, da tortura e da censura em 1964. Para tanto, utilizam-se de propaganda negacionista, assim como o governo e as Forças Armadas, procurando convencer a população de que não houve ditadura nem tortura naquela época, ${ }^{5}$ embora ameacem, claramente, armar o povo contra as instituições democráticas. "E nuvens, lá no mata-borrão do céu, chupavam manchas torturadas. Que sufoco!".

\footnotetext{
${ }^{1}$ O que é protofascismo? Disponível em: www.dicio.com.br. Acesso em: 20 maio 2020.

${ }^{2}$ BENJAMIN, Cid. Estado Policial: como sobreviver. Rio de Janeiro: Civilização Brasileira, 2019.

${ }^{3}$ Trecho da música Vai passar, de Chico Buarque de Holanda.

${ }^{4}$ REVISTA MOTRIVIVÊNCIA. Florianópolis, v. 30, n. 56, dez. 2018. Disponível em: https://bit.ly/2X3RnsV. Acesso em: 20 maio 2020.

${ }^{5}$ IANNI, Otávio. A ditadura do grande capital. São Paulo: Expressão Popular, 2019, p. 18-19.
} 
Diante desta situação de crise generalizada, é necessário não olvidar do que está por trás de todo esse imbróglio: a ditadura do grande capital. Esse dado histórico é emblemático, levando-se em conta que o governo canhestro de Bolsonaro recebe o apoio das Forças Armadas e da grande burguesia financeira brasileira e internacional, principalmente do imperialismo estadunidense, representado por Trump. Este espectro da barbárie da ditadura do capital e a possibilidade de retorno à tortura existente de 1964 a 1985 atormentam os brasileiros. Na realidade, a grande ditadura se realizou a partir da relação entre a grande burguesia e o regime militar, além da inspiração em um Estado fascista, que, através do planejamento tecnocrático, foi erigido pela "força produtiva complementar". ${ }^{6}$ Tudo isso, via de regra, serve para favorecer parcelas determinadas do grande capital. E, assim, todo esse quadro, tanto agora como antes, ocorre num ambiente de violência simbólica e real, de expropriações, tentativas de intervenção, perseguições em geral e, particularmente, à liberdade de expressão, criminalização dos movimentos sociais e sindicais, paranoia persecutória sobre os partidos de esquerda e intensa repressão política. ${ }^{7}$ Em 1964, o lema era "segurança e desenvolvimento", dístico que acobertava, como na atualidade, uma política de favorecimento ao imperialismo, sob a forma do grande capital monopolista, que se assentava na superexploração da força humana de trabalho. O chamado 'milagre brasileiro' também se encontrava, a exemplo de hoje, numa dimensão fascista e abertamente anticomunista. Esse período da nossa história, se comparado com o governo Bolsonaro, demonstra as inequívocas similitudes entre os fatos históricos ocorridos naquela altura e a chamada democracia liberal, hoje vigente.

O fato é que a nova ditadura do capital já está posta e suscita um tema muito complexo para o debate atual sobre a politização das Forças Armadas: a militarização das instituições democráticas, da política, da economia, da cultura e da educação. Os militares, desde a campanha pelo impeachment, ganharam mais espaços, com aumento de gastos e o comando do Ministério da Defesa; daí por diante, foram recuperando paulatinamente as forças, ao sopro do fole do governo Bolsonaro. Neste governo, eles passaram a assumir o papel de políticos profissionais, tornando-se quase um partido militar e ocupando os altos cargos da República. ${ }^{8}$ Isso é bem visível, não só pelo número de militares que majoritariamente compõem o governo Bolsonaro mas também pelas práticas ditatoriais, militaristas (ex.: escolas cívico-militares) e milicianas, que, de maneira clara, arrogante e autoritária, recrudescem o temor pelo retorno aos tempos idos de 1964. Assim, o que se vê é um jogo medíocre dos militares, ora mostrando as garras, elogiando a ditadura e tecendo loas à tortura cruel engendrada por seus pares (o vice-presidente Mourão), ora fazendo a estratégia de 'vistas grossas' aos malfeitos de Bolsonaro e, com isso, lentamente se fortalecendo. Mas o fato é que esses senhores permitem que os milicianos treinem suas táticas, tanto em instalações militares quanto em frente ao Planalto, semanalmente, proferindo ameaças ao STF e ao Senado, incitando a violência verbal e armada. Os militares, nesse sentido, quando se fala em golpe ou autogolpe, com irresponsabilidade e vilania política, não economizam ameaças explícitas de uma suposta guerra civil e convulsão social (Generais Heleno e Mourão), tampouco escondem a defesa dos valores da ditadura, ao renderem homenagens a consumados torturadores (Ustra). Tudo isso faz parte do pacote do autogolpe, que, entre outras coisas, tem por objetivo intervir no STF, transformando-o em um Tribunal Militar.

Além dos cargos mais altos do Executivo, os militares, paulatinamente, vão ocupando quadros menores nos ministérios e nas secretarias de governo (a exemplo dos oito militares recentemente incorporados ao Ministério da Saúde). São eles que, depois de 50 anos, acenam com a volta do AI-5, mostrando-nos que ele "ainda não terminou de acabar", ${ }^{9}$ e, por isso, temos que persistir na luta incessante de resistência, a fim de que os campos de concentração e a ditadura nunca mais tenham

\footnotetext{
${ }^{6}$ IANNI, 2019, p. 18-19.

${ }^{7}$ BENJAMIN, 2019.

${ }^{8}$ SECCO, Lincoln. Tropa politizada: o partido militar. Le Monde Diplomatique, São Paulo, Ano 12, n. 146, p. 18, set. 2019. Disponível em: https://bit.ly/36uDPd2. Acesso em: 20 maio 2020.

${ }^{9}$ MIYADA, Paulo (org.). AI-5 50 Anos: ainda não terminou de acabar. São Paulo: Martins Fontes, 2018, p. 13.
} 
morada no nosso tão sofrido Brasil. Esses episódios nos fazem repensar o país e o modelo de sociedade que queremos construir, durante e após a pandemia; um modelo para além do reino das meras necessidades humanas, ou seja, um reino de liberdade, felicidade individual e coletiva. Uma sociedade em que possamos lutar sempre pela vida e a saúde da coletividade, superando a exploração do trabalho e a opressão social. Nesses meandros, fala-se de golpe ou autogolpe, mas o fato é que precisamos urgentemente denunciar e defender o Brasil desses generais, que, covardemente, segundo a Comissão Nacional da Verdade, fizeram desaparecer, torturar e matar pelo menos 434 pessoas, entre mortos e desaparecidos políticos, durante o período da ditatura. ${ }^{10}$

Por tudo o que vivemos naquele Estado ditatorial, seria recomendável que cantássemos, em todos os espaços possíveis, a fim de lembrar de "uma dor assim pungente", gestada nos porões do DOI-Codi (Destacamento de Operações de Informação - Centro de Operações de Defesa Interna), órgão de inteligência e repressão subordinado ao exército brasileiro durante o regime militar. Embora a ditadura seja anacrônica, não custa ficar atento a estes versos dolorosos: "Chora a nossa Pátria, mãe gentil, choram Marias e Clarisses no solo do Brasil”. Portanto, temos que entender, peremptoriamente, que é hora de lutar pelo que restou da nossa frágil democracia em construção, pois ainda "dançamos na corda bamba de sombrinha e, em cada passo dessa linha, podemos nos machucar". Diante da força desses versos, só nos resta lutar pela imediata desmilitarização das políticas de Segurança Pública, ${ }^{11}$ pelo desarmamento da população, entre outros temas, enfim, pela desmilitarização da sociedade brasileira. Essa questão é crucial para nós, ativistas, intelectuais, editores de revista, militantes sociais e dirigentes sindicais, que defendemos uma política que garanta o cumprimento e o respeito aos direitos humanos e à justiça. Esse posicionamento político é de fundamental importância, especialmente se levarmos em conta que vivemos em uma sociedade marcada por enorme desigualdade social, por racismo estrutural e violência contra a classe trabalhadora empobrecida, contra a mulher, os idosos, os negros, os indígenas e a população LGBTQI+, entre outras categorias sociológicas. Ao fim e ao cabo, só existe uma saída: "chegar ao fundo do poço... e continuar cavando", redimensionando uma metáfora usada por Serge Halimi. ${ }^{12}$ Isso implica gritar, em qualquer tempo ou espaço: ditadura, nunca mais! AI-5, nunca mais! Censura, nunca mais! Tortura, nunca mais!

Se a letra do emblemático hino-canção $O$ bêbado e a equilibrista encerra tantas lições de vida e política, os versos de Querelas do Brasil, lindamente compostos por Aldir Blanc em parceria com Maurício Tapajós, também trazem, no bojo de suas metáforas e signos, entre outras ideias, uma crítica à perda da nossa soberania, provocada pelo 'entreguismo' das nossas riquezas ao capital internacional (Amazônia, Pré-Sal, Base de Alcântara) e pela sangria desatada das privatizações sem limites. Isso tudo sem contar as aproximações e supostas negociatas entre Moro, ex-ministro da 'justissa brazyleira', e o FBI. A exemplo de Bolsonaro para com Trump, ajoelhou-se aos pés dos EUA e vendeu, no âmbito da Lava-jato, também chamada 'Vaza-jato', assuntos de segurança e soberania nacionais para o FBI e a CIA, ou seja, para o Departamento de Justiça dos Estados Unidos. Essa aproximação de Moro com o FBI vem sendo percebida há algum tempo, principalmente por ocasião de uma licença não remunerada de cinco dias, que Moro tirou em julho do ano passado, pouco depois da publicação dos documentos da Vaza-jato pelo site The Intercept, supostamente para tratar da parceria entre a Polícia Federal e o FBI, a polícia federal norte-americana. Sendo assim, cogita-se que o ex-ministro tenha se reunido com o FBI em Washington, segundo documentos obtidos via Lei de Acesso à Informação (LAI). Vale lembrar que Moro é supostamente o candidato às eleições

${ }^{10}$ MEMORIAL de mortos e desaparecidos. Memórias da ditadura militar, [S. l.], [201-?]. Disponível em: https://bit.ly/36AAhpZ. Acesso em: 20 maio 2020.

${ }^{11}$ SOARES, Luiz Eduardo. Desmilitarizar. São Paulo: Boitempo, 2019.

${ }^{12}$ HALIMI, Serge. Chegar ao fundo do poço... e continuar cavando. Le Monde Diplomatique, São Paulo, Ano 12, n. 140, p. 2, mar. 2019. Disponível em: https://bit.ly/3cZysoN. Acesso em: 20 maio 2020. 
presidenciais de 2022, sob a tutela dos EUA e da mídia hegemônica, e não das mídias alternativas, ${ }^{13}$ sobretudo da Rede Globo de televisão e de seus conglomerados.

As metáforas de Aldir Blanc e Maurício Tapajós - "O Brazil tá matando o Brasil”, "Do Brasil, SOS ao Brasil”" - carregam, em seus signos, em primeiro lugar, o alerta sobre a desesperadora situação política, sanitária e econômica em que se encontra o Brasil sob o necrocapitalismo de Bolsonaro. Na realidade, pode-se dizer que se trata de um 'Estado suicidário', em que todos nós fazemos parte de um experimento. O destino de nosso corpo, assim como a sua morte, faz parte de um experimento de tecnologia social, de uma nova forma de gestão da vida e da morte, da qual o uso da cloroquina, 'receitada' pelo presidente anticiência, é um dos mais patentes exemplos. Tanto agora, durante a quarentena, quanto antes da pandemia, é visível a atuação de um 'Estado suicidário'. Este modelo de Estado corresponde a um novo estágio dos modelos de gestão imanentes ao neoliberalismo, em sua face mais cruel, a da fase terminal. Neste caso, o Estado brasileiro não é apenas o gestor da morte, ele é o ator de sua própria tragédia, o artífice de sua própria implosão. Não se trata apenas da necropolítica, na qual o Estado opera como coveiro e gestor da morte e do desaparecimento dos seus opositores - considerados como seus principais inimigos. ${ }^{14}$ Nesse sentido, subjaz aos versos a postura de desprezo genocida do antipresidente pela vida dos trabalhadores e trabalhadoras empobrecidos, isto é, pelos mais de 16 mil mortos, nesta altura, pela Covid-19.

Em segundo lugar, também está subjacente às metáforas "O Brazil tá matando o Brasil" e "Do Brasil, SOS ao Brasil” uma sequência inominável de destruições, já descritas nos dois últimos editoriais, tais como: a queimada intencional da Amazônia; o óleo nas praias e nos rios do Brasil; a destruição dos direitos dos trabalhadores (desemprego estrutural e precarização do trabalho) - desde sempre, mas fundamentalmente durante o coronavírus -; o ódio à ciência e à educação, em todos os níveis, mas sobretudo à universidade pública; a destruição do patrimônio público em geral; o cerceamento da demarcação e a abertura das terras indígenas à exploração da iniciativa privada, ou seja, dos "reis do agronegócio, donos do agrobiz", das "bancadas do boi e da bala"15 e dos garimpeiros. Esse projeto está sendo paulatinamente levado a cabo pelo Ministério do Meio Ambiente, tendo à frente a Fundação Nacional do Índio (Funai) e o Instituto Nacional de Colonização e Reforma Agrária (Incra). Essa barbaridade vem provocando o extermínio dessas populações, tanto de etnias já 'civilizadas' quanto dos chamados 'povos isolados', das florestas, dos animais, além do envenenamento dos alimentos e da poluição dos rios, causados pela permissiva exploração, por parte do garimpo, de terras pertencentes aos povos originários. Esse crime ambiental contra a Amazônia e as populações indígenas ficou evidenciado pela fala do Ministro Ricardo Salles, que admitiu, recentemente, na fatídica reunião ministerial com o antipresidente, aproveitar o coronavírus para destruir mais ainda a Amazônia: "Então, para isso precisa ter um esforço nosso aqui, enquanto estamos nesse momento de tranquilidade, no aspecto de cobertura de imprensa, porque só se fala de Covid-19, e ir passando a boiada e mudando todo o regramento e simplificando normas." 16

${ }^{13}$ HAUBRICH, Alexandre. Mídias Alternativas: a palavra da rebeldia. Florianópolis: Insular, 2017.

${ }^{14}$ SAFATLE, Vladimir. Bem-vindo ao Estado suicidário. Jornal GGN, [S. l.], 25 mar. 2020. Disponível em: https://bit.ly/3enFcwO. Acesso em: 20 maio 2020.

15 Trecho da música Reis do agronegócio, de Chico César.

${ }^{16}$ PRAZERES, Leandro; FERREIRA, Paula. Órgão do MPF recomenda investigação contra Salles por crimes de responsabilidade e de improbidade. G1, [S. l.], 27 maio 2020. Disponível em: encurtador.com.br/blnR3. Acesso em: 27 maio 2020. 


\section{Pandemia e pandemônio no Brasil: ${ }^{17}$ continuidade das barbáries no 'covidário' de Bolsonaro e "Lá vem o Brasil descendo a ladeira"18}

Neste editorial, revisitamos as barbáries, os verdadeiros crimes de lesa-pátria e lesahumanidade cometidos por Bolsonaro ao dar continuidade ao seu plano de extermínio do Brasil, principalmente no período entre março e abril, quando construímos nosso último editorial. De lá para cá, em menos de dois meses, percebemos um recrudescimento dos decretos presidenciais e das medidas provisórias, além de uma série de episódios destrutivos das políticas públicas e sociais, em meio ao enorme impacto causado pela Covid-19. Assim, destacam-se alguns pontos: o fortalecimento dos militares nos cargos de governo; o ódio à esquerda e ao suposto 'comunismo'; a sanha desmedida pela privatização de tudo; o agravamento da pandemia do coronavírus, que provocou pandemônio, crises e rupturas entre o presidente, os governadores e os prefeitos; a insistência do negacionismo e o descaso pela Ciência; o desestímulo ao isolamento social e a defesa de retorno imediato ao trabalho, dos quais decorrem o crescimento do número de óbitos e a fragilidade do Sistema Único de Saúde (SUS), sucateado desde o governo Temer. Além da irresponsabilidade negacionista da ciência, Bolsonaro deu prosseguimento à ofensiva reacionária e autoritária contra as universidades e institutos de pesquisa, contra a ciência, a tecnologia e a cultura, fato que nos mostra claramente o efeito da articulação entre o capitalismo dependente e o protofascismo sobre as políticas públicas de saúde, educação e ciência. ${ }^{19}$

O mais perverso de tudo isso é que os seguidores fanáticos e fundamentalistas de Bolsonaro chegaram a fazer carreatas e manifestações ao redor de hospitais públicos e privados, zombando dos mortos e doentes internados, na esteira do próprio Bolsonaro, que, instado a se manifestar sobre o número de mortos - àquela altura, mais de cinco mil -, disse: - "E daí?". Esse ódio ao outro, movido pelo descaso com a ciência, revela também uma espécie de banalização ou naturalização da morte e de outros fenômenos sociais e históricos, como por exemplo, os campos de concentração nazistas, que ceifaram as vidas de milhares de crianças, homens, mulheres, velhos e velhas. Nessa mesma direção, não podemos deixar de mencionar a banalização de classe, que alimenta uma indiferença para com as desigualdades sociais, verificada, fundamentalmente, pelo descaso, por parte das classes médias e das elites, com o número de pobres, desempregados ou subempregados.

Para essa gente, o que vale são os números e as estatísticas da economia. Dez, vinte ou trinta mil mortos não causa qualquer prurido humanitário nessa manada fundamentalista; são uns monstros de mentalidade autoritária, remanescentes dos campos de concentração: Auschwitz, nunca mais! Essa gente neoliberal, miliciana e neopentecostal, mesmo quando é obrigada a conviver diuturnamente com cenas lúgubres, como o comboio de ambulâncias e caminhões frigoríficos cobertos de corpos que desfila nas cidades, em direção aos cemitérios, para enterros em valas comuns, não é capaz de derramar uma lágrima, pelo contrário, anda com caixões a tiracolo em suas manifestações, espalhando o vírus do ódio, eivada de alienação e perversão. Diante de tamanha crueldade, a pergunta que se impõe é: como uma sociedade consegue naturalizar estas mortes como a brasileira as naturaliza? Todo esse quadro é liderado pela personalidade autoritária e fascista de Bolsonaro e seu séquito de celerados. Aliás, o presidente, juntamente com as Forças Armadas e os empresários, é responsável por esse número de óbitos, pois "Quem cala sobre teu corpo, consente na tua morte, talhada a ferro e fogo nas profundezas do corte". ${ }^{20}$

${ }^{17}$ AUGUSTO, Cristiane Brandão; SANTOS, Rogerio Dultra. Pandemias e Pandemônio no Brasil. São Paulo: Tirant lo Blanch, 2020. p. 17.

${ }^{18}$ Música de Moraes Moreira.

${ }^{19}$ LEHER, Roberto. Autoritarismo contra a universidade. São Paulo: Expressão popular, 2019, p. 23.

${ }^{20}$ Trecho da música $O$ menino, de Milton Nascimento 
Outra questão que pode mobilizar os pesquisadores diz respeito às problemáticas da saúde e do sofrimento no trabalho durante a pandemia. Portanto, temos um quadro complexo de saúde físicomental que se explicita como problema de saúde pública e coletiva, não apenas para os infectados, mas também para aquelas pessoas que são obrigadas a ficar em casa, principalmente os trabalhadores empobrecidos pelas políticas neoliberais. Nessa perspectiva, cabe estabelecer uma variável de classe social, haja vista que os mais pobres tendem a ter, provavelmente, maiores dilemas existenciais e materiais (ligados ao desemprego, ao subemprego, à fome, às moradias insalubres e superlotadas, à falta de saneamento básico, entre outras precarizações da vida). De todos os modos, diante dos bombardeios, ataques e desmontes das políticas públicas e sociais, convém voltar a pensar na possiblidade de estarmos todos "doentes de Brasil", tema que foi objeto de nossa reflexão na penúltima edição. $^{21}$

Na edição retrasada, ainda em 2019, trouxemos a questão da saúde físico-mental da sociedade brasileira em meio aos desmandos de Bolsonaro e sua lista de maldades, ainda muito antes do coronavírus. Naquela edição, abordamos a sanha neoliberal e autoritária do governo Bolsonaro como causa do sofrimento e do adoecimento da sociedade brasileira. No texto Doente de Brasil, ${ }^{22}$ Eliane Brum descreve o aumento do número de pessoas queixando-se de angústia, depressão e síndrome do pânico nos consultórios de psiquiatria, de clínica geral, de medicina interna e de cardiologia, além de taquicardia, tontura e falta de ar, entre outras doenças. Todas essas enfermidades, lamentavelmente, também atingem os profissionais da saúde e da segurança pública, que, dia após dia, morrem nos fronts de combate à Covid-19, as ruas e os hospitais, sejam eles públicos, privados ou de campanha. Estima-se que o número de profissionais da saúde e da segurança pública (e familiares) infectados com o coronavírus ultrapasse dois milhões. Só da saúde, até então, são 29 profissionais de enfermagem mortos e 3.661 afastados de suas funções por suspeita ou confirmação positiva de Covid$19 .^{23}$

Pois bem, temos agora a Covid-19, então a nova pergunta é: como andará a saúde das pessoas que já estavam doentes em decorrência das malfeitorias de Bolsonaro, agora, com a chegada do coronavírus? Essa resposta merece aprofundamento nas pesquisas daqui por diante, mas alguns sites já apontam que as principais doenças de jovens e crianças na era da Covid-19, em razão da quarentena longe da escola, são: insônia, ansiedade, angústia, depressão e síndrome do pânico. Isso vale também para os adultos trabalhadores, sobretudo no trabalho informal e precário, por causa das exíguas possibilidades de se inserirem no mundo do labor. ${ }^{24}$

Além desses temas, existem outros que podem ser objetos de pesquisa nas ciências humanas e sociais, com ênfase no período da pandemia, por exemplo: a pandemia do capitalismo global: o Brasil e América Latina na geopolítica mundial da Covid-19; o uso político da pandemia; póspandemia: amanhã vai ser outro dia?; O mundo em crise e o pandemônio na política; necrocapitalismo e neofascismo em tempos de crise econômica, sanitária e política; pandemia: qual a biopolítica?; o populismo de extrema direita em tempos virais; pandemônio nos poderes do Brasil e a pandemia da Covid-19; a hipertrofia judicial e as medidas neoliberais; Bolsonaro e os poderes na pandemia do conflito; Covid-19, direitos humanos e a rede solidária em defesa da vida; pandemia da precarização do trabalho; os sindicatos e a tutela do trabalho; entre outros temas. ${ }^{25}$ Especificamente na Educação Física: as reflexões sobre o corpo e o lazer antes e após a pandemia; a volta da militarização do corpo

${ }^{21}$ BRUM, Eliane. Doente de Brasil. El País, [S. l.], 2 ago. 2019. Disponível em: https://bit.ly/2TK8Nca. Acesso em: 20 maio 2020.

${ }^{22}$ Ibid.

${ }^{23}$ FALTAM EPIs e sobra descaso com profissionais da área da saúde durante pandemia. RDC, Rio Grande, 23 abr. 2020. Disponível em: https://bit.ly/3c9aTIK. Acesso em: 20 maio 2020.

${ }^{24}$ CORONAVÍRUS: o impacto da doença na saúde mental de adolescentes e jovens. G1, [S. l.], 4 abr. 2020. Disponível em: https://glo.bo/3d8P9hE. Acesso em: 20 maio 2020.

${ }^{25}$ AUGUSTO; SANTOS, 2020, p. 17. 
na sociedade (ou especificamente na formação de profissionais ou em aulas de Educação Física); entre outras possibilidades de abordagem.

\section{O trabalho em tempos de coronavírus}

Na edição passada, ${ }^{26}$ discorremos, introdutoriamente, sobre a crise de dominação do capital, que segue historicamente seu curso e se alastra com seus problemas, acirrando contradições cada vez mais explosivas. Trata-se de crise forjada por um sistema destrutivo, que representa a decadência, o pauperismo e a intolerância, bem como a tirania e a barbárie. Parece uma fábrica enlouquecida, na qual se produzem tanto coisas e ilusões quanto guerras e destruições. ${ }^{27}$ Contudo, em tempos de coronavírus, podemos falar de uma tríplice crise do capital, isto é, o capitalismo enfrenta pelo menos três grandes crises, que se interconectam. ${ }^{28}$ Trata-se de uma crise de saúde, induzida pela pandemia, que rapidamente acendeu o pavio de uma explosiva crise econômica, cujas consequências para a estabilidade financeira mundial são incomensuráveis. Além do mais, essa crise financeira eclode no contexto de uma crise climática sem precedentes, da qual as queimadas na Amazônia são um bom exemplo. Há apenas dois meses, as imagens inquietantes de trabalhadores exaustos, que encheram os meios de comunicação, não eram de trabalhadores da saúde, mas sim de bombeiros. ${ }^{29}$ Em grande parte dessas edições, estiveram presentes as reflexões sobre a flexibilização do trabalho, que vem corroendo os direitos dos trabalhadores em geral, inclusive na Educação e na cultura corporal da Educação Física, culminando em desemprego estrutural e em subemprego, materializado no trabalho precário, informal, intermitente, entre outras formas mais perversas, que veremos no decorrer do texto.

Nesse emaranhado de flexibilizações e precarizações do trabalho, principalmente durante a pandemia da Covid-19, as corporações aproveitam para engendrar a 'uberização' e expandir a lógica da 'pejotização' (pessoas jurídicas trabalhando como empregados, a fim de burlar a legislação), o que faz florescer uma nova modalidade de trabalho: o 'escravo digital'. Some-se a isso uma massa cada vez mais crescente de 'empreendedores', isto é, uma mescla de 'burguês-de-si-próprio' com 'proletário-de-si-mesmo'. E tudo isso acontece no intuito de disfarçar o assalariamento. Esses gestores públicos e privados, apesar de defenderem a 'responsabilidade social e ambiental', assim como incontáveis corporações, praticam mesmo é a informalidade ampliada, a flexibilização desmedida, a precarização acentuada e a destruição cronometrada da natureza. Aquilo que era exceção virou regra no neoliberalismo. ${ }^{30}$

Não bastassem essas novas formas de trabalho, no âmbito dessa lógica da informalidade, o que exsurge é mais flexibilidade e precarização para os professores das redes municipais e estaduais. Eles estão perdendo seus direitos em razão do trabalho precário e temporário das chamadas Organizações Sociais (OS), que têm causado muitos estragos na educação pública de qualidade, gratuita e socialmente referenciada. Sob a égide da informalidade e das terceirizações de serviço, o principal papel dessas OS é substituir o papel do Estado na gestão dos bens público. Essa lógica serve para qualquer setor (educação, saúde e outros), sob o argumento de que o poder público deve transferir

${ }^{26}$ REVISTA MOTRIVIVÊNCIA. Florianópolis, v. 32, n. 61, jan./mar. 2020. Disponível em: https://bit.ly/2B8vy35. Acesso em: 20 maio 2020.

${ }^{27}$ IANNI, 2004, p. 9.

${ }^{28}$ MAZZUCATO, Mariana. A tríplice crise do capitalismo. Fundação Perseu Abramo, [S. l.] 7 abr. 2020. Disponível em: https://bit.ly/2B7BxoN. Acesso em: 20 maio 2020.

${ }^{29}$ Ibid.

${ }^{30}$ ANTUNES, Ricardo. O privilégio da servidão: o novo proletariado de serviços na era digital. São Paulo: Boitempo, 2016. p. 33. 
a terceiros a responsabilidade de ofertar determinado serviço, supostamente com maior participação e controle social, a fim de que seja executado de forma mais eficiente, econômica e eficaz. ${ }^{31}$

Outra forma de trabalho que vem crescendo muito é a chamada 'indústria 4.0'. A proposta é veiculada em todos os cantos do mundo, visando à consolidação do projeto neoliberal. Nos termos com que é apresentada, provavelmente terá como consequência a criação de um núcleo pequeno de novos trabalhos, aqueles mais sintonizados com as tecnologias de informação e comunicação, ao preço de uma destruição em massa, em escala monumental, nos países capitalistas do Norte e mais ainda nos do Sul, de um conjunto de empregos, substituídos pela internet, pela inteligência artificial, pela impressão 3D, pelo big data e pelo arsenal tecno-informacional digital, que, se fosse voltado para o atendimento das necessidades sociais humanas, teria outro impacto sobre a produção da vida dos trabalhadores. No entanto, a finalidade desse processo é a devastação do trabalho para manutenção da lógica perversa do capital, e não uma vida cheia de sentido, para a qual o trabalho é atividade vital. ${ }^{32}$

Todos os trabalhadores e as trabalhadoras supramencionados fazem parte de um grupo cada vez menor, que poderá chegar ao topo dos assalariados. Não obstante isso, a instabilidade poderá levá-los a ruir diante de qualquer oscilação do mercado, com seus tempos, movimentos, espaços e territórios em constante mutação.

Durante a pandemia do coronavírus, vivenciamos o "falso dilema entre salvar vidas ou salvar a economia". ${ }^{33}$ Nesse sentido, a falsa polêmica busca responder se o Estado, num cenário de pandemia mundial, deveria se empenhar em salvar as vidas dos trabalhadores e trabalhadoras, mediante o isolamento social da quarentena, ou priorizar a economia, num momento tão vital e dramático, sobretudo para a fração da classe trabalhadora que vive nas periferias das grandes cidades, com salários de miséria, sem saneamento básico, em moradias precárias e dependente de um sistema de saúde tão vulnerável como o SUS. Trata-se de um falso dilema, que só cabe na cabeça de uma mentalidade doentia, desumana e perversa como a de Bolsonaro. Ele nunca escondeu sua preferência pela volta ao trabalho, às escolas e às demais atividades, essenciais ou não, porque, segundo ele, $o$ isolamento social, ao fim e ao cabo, seria responsável pela crise econômica. O antipresidente, mancomunado com sua corte miliciana, neopentecostal e fascista, defendeu sempre o caminho da liberação dos comércios e mercados, para favorecer os grandes negócios do capital. O lucro está acima de tudo, acima da vida das pessoas. Somos da opinião de que não pode haver, em tempos de pandemia, uma dicotomia entre salvar a vida e a saúde das pessoas ou salvar a economia, mas, primeiramente, salvemos as vidas, evitando as mortes.

Enquanto isso,

[...] a pandemia do coronavírus está escancarando a profunda desigualdade e vulnerabilidade social, e a precariedade dos serviços públicos essenciais. Em meio a esse drama social, o setor financeiro se utiliza de oportunismo abominável e exige a aprovação da PEC 10/2020, que promove a transferência de trilhões de recursos públicos para os bancos, aumentando ainda mais os seus lucros. ${ }^{34}$

${ }^{31}$ JUNQUEIRA, Nadia. O que são OS ou organizações sociais? A Redação, [S. l.], 28 ago. 2011. Disponível em: https://bit.ly/2zsgkFL. Acesso em: 20 maio 2020.

${ }^{32}$ PEIXOTO, Heitor. Uberização nos leva para a servidão, diz pesquisador. Entrevista com Ricardo Antunes. Congresso em foco, Brasília, 25 jul. 2019. Disponível em: https://bit.ly/3epRdSF. Acesso em: 20 maio 2020.

${ }^{33}$ SILVA, Ivone. O falso dilema entre salvar vidas ou salvar a economia. Brasil de Fato, Rio de Janeiro, 21 abr. 2020. Disponível em: https://bit.ly/2AiCKJh. Acesso em: 20 maio 2020.

${ }^{34}$ FATORELLI, Maria Lúcia. O golpe de trilhões em plena Pandemia. Auditoria cidadã da dívida, [S. l.], 2 maio 2020. Disponível em: https://bit.ly/2TN6wgq. Acesso em: 20 maio 2020. 
Postas essas questões sobre o mundo do trabalho no âmbito da pandemia do coronavírus, consideramos relevante destacar algumas medidas que nos puseram em alerta. Talvez a mais drástica tenha sido o fato de o governo Bolsonaro usar a pandemia para congelar os salários por 18 meses, até dezembro de 2021, e reduzir o poder aquisitivo de servidores e servidoras públicos(as) civis, nas esferas municipais, estaduais, distrital e federal, nos três Poderes. Os Projetos de Lei Complementar (PLP) 149/2019 e 39/2020, aprovados pelo Senado, podem ser um passo para aprofundar a Emenda Constitucional $n^{\circ}$ 95/2016 (EC n ${ }^{\circ}$ 95/16), a chamada PEC da Morte ou PEC do fim do mundo, que congelou por 20 anos os investimentos do Estado em diversos setores sociais do país. Isto significa dizer que é injusto jogar o custo da pandemia nas costas dos trabalhadores, que foram chamados pelo Ministro Guedes de "parasitas, assaltantes, saqueadores, chantagistas e inimigos do Estado", ${ }^{35}$ tanto os do serviço público quanto os da iniciativa privada. Isso porque o Estado brasileiro tem dinheiro para bancar os custos dessa crise. A prova disso é que, em março, quando estados, municípios e o Distrito Federal decretaram isolamento social, o presidente do Banco Central, Roberto Campos Neto, providenciou um pacote de ajuda com $\mathrm{R} \$ 1,2$ trilhão, ou 16,7\% do Produto Interno Bruto (PIB), incluindo ações que ainda estão em estudo, para socorrer os bancos durante a crise da pandemia. Quer dizer, de novo: dinheiro há, mas apenas para socorrer os mais ricos, e não a classe trabalhadora, que até então vivia do trabalho e hoje está imersa no desemprego e no subemprego, nas filas do SUS e dos bancos, para mendigar os míseros 600 reais de 'auxílio emergencial', que no fundo são uma verdadeira esmola. ${ }^{36}$

Além desses fatores, que terão reflexos no período pós-pandemia, enumeramos os seguintes pontos: as dificuldades encontradas pelos trabalhadores informais, sem carteira assinada e sem direitos; a ameaça de parte do patronato em demitir quem ficasse de quarentena; o dilema vivido pelos trabalhadores e trabalhadoras da saúde diante do risco diuturno de contágio por coronavírus nos hospitais públicos e privados, em UPAs, centro de saúde, hospitais de campanha e UTIs, especialmente porque centenas deles já foram a óbito; a situação dos professores, obrigados a dar exaustivas aulas online e a corrigir tarefas de muitas crianças, fato este que fez com que pais e professores se organizassem para não permitir o uso desse tipo especial de aula depois de cessada a pandemia, a fim de não desvalorizar o trabalho docente presencial e instituir em seu lugar o ensino remoto, principalmente na educação básica, o que só beneficiaria o chamado 'capital educador', movido pelas grandes corporações do capital nacional e internacional. ${ }^{37}$ Nesse sentido, a pergunta é: quem vai pagar a conta?

\section{A Educação durante pandemia: reflexões, práticas e ingerências do 'capital educador'}

Como vimos, do ponto de vista de sua materialidade e das suas contradições, tanto antes quanto durante a pandemia, o trabalho se apresenta como uma problemática cada vez mais complexa, em razão do processo de flexibilização, que provoca uma plêiade de precarizações e gera desemprego estrutural e subemprego, imprimindo as marcas hiperneoliberais do interminável 'privilégio da servidão'.

Quando se leva em consideração as intrínsecas relações entre trabalho e Educação na perspectiva do capital, pode-se dizer que, assim como no trabalho, no atual neoliberalismo letal, há

35 O MINISTRO defendeu a reforma administrativa para acabar com supostos "privilégios". Sindjusfem, Campo Grande, 7 fev. 2020. Disponível em: encurtador.com.br/esuEK. Acesso em: 20

${ }^{36}$ CARLA, Maria. Governo Bolsonaro usa a pandemia para congelar salários e reduzir o poder aquisitivo de servidores. Sindprof, Brasília, 4 maio 2020. Disponível em: https://bit.ly/3c6Ad2m. Acesso: 20 maio 2020.

${ }^{37}$ EVANGELISTA, Olinda; SOUZA, Artur. Pandemia! Janela de oportunidade para o capital educador. Contrapoder, [S. l.], 15 abr. 2020. Disponível em: encurtador.com.br/aexBY. Acesso em: 20 maio 2020. 
uma onda de precarização, flexibilização e mercantilização também na Educação, haja vista a destruição das políticas educacionais, de que tratamos na edição passada. ${ }^{38}$

Todavia, se quisermos romper com a lógica do capital e construir uma alternativa educacional significativamente diferente, ou seja, para além do capital e, consecutivamente, para além da exploração dos trabalhadores, teremos que pensar e agir contra a sociedade da mercadoria e a propriedade privada dos meios de produção na Educação. ${ }^{39}$ Estamos nos referindo aos estudos de Olinda Evangelista e Artur Souza, ${ }^{40}$ que denunciam as manobras de um grupo de empresas (Advent, Kroton, Anhanguera/Uniban, Aties, Abril, BeVry, GP investimentos, Estácio, Lauvate, Pátria Blackstone, entre outras), intituladas pelos autores 'capital educador', na categoria de análise. O capital educador veio sorrateiramente se infiltrando no Ensino Superior brasileiro ao longo dos últimos governos. No governo Bolsonaro, utiliza-se do deplorável projeto 'Future-se'. Agora, porém, essas empresas estão investindo fortemente na Educação Básica, buscando a formação de docentes para a escola pública via privatização. Esse processo, que os autores chamam de 'capital educador', consiste num assalto à escola básica e pública, agora do Ensino Fundamental ao Ensino Superior.

Essas reflexões dizem respeito não só aos fundamentos teórico-práticos da educação em geral, mas também aos da Educação Física. Isto porque os professores de Educação Física, que atuam em universidades públicas e privadas, assim como nas redes municipais e estaduais de ensino, da Educação Básica até o Ensino Médio, vêm sofrendo na pele as agruras das destruições neoliberais, através da mercantilização das políticas educacionais, oriundas de opções políticas forjadas ao longo de décadas, que conferiram ao setor privado a possibilidade de construir uma verdadeira fábrica de diplomas no Brasil, altamente lucrativa. ${ }^{41}$ Isto é, a educação, principalmente a escolar, vem cada vez mais se amoldando à 'escola neoliberal', que considera a educação como um bem privado e econômico. ${ }^{42}$ Os efeitos deletérios desse tipo de política educacional reverberam nas práticas concretas dos professores, inclusive os de Educação Física, que, como os demais, viveram as desventuras da formação para o capital nas últimas décadas. Essas destruições dizem respeito a direitos que incidem igualmente nos diversos níveis de ensino. Estamos nos referindo à suspensão dos concursos, à precarização dos contratos de trabalho terceirizado nas redes públicas e à consequente precarização do trabalho dos professores nas universidades federais. Isso significa dizer que tanto os professores de sala de aula quanto os da Educação Física (que atuam em quadras, ginásios de esporte, academias e práticas de lazer) se encontram no mesmo 'barco', quando se fala em superexploração da força humana do trabalho docente.

Aliás, na penúltima edição, de 2019, já alertávamos sobre a crescente mercantilização da educação de nível superior no Brasil, que desponta sob a égide dos interesses do grande capital, em nível nacional e internacional. Ela faz parte da crescente financeirização da economia política, que foi imposta pelo governo Bolsonaro como alternativa para o 'futuro do presente' das universidades brasileiras, assim como para a educação em geral. Naquela edição, criticamos a manobra de destruição do Ensino Superior perpetrada por meio do 'Future-se', um projeto de privatização das universidades e de devastação do patrimônio público, cuja intenção é abrir as portas para grandes grupos financeiros.

${ }^{38}$ SILVA; PIRES; PEREIRA. A política de devastação e autoritarismo de Bolsonaro, 'o exterminador do Brasil': 'Future-se' para o abismo, sofrimento e adoecimento de Brasil e a urgente resistência ativa. Motrivivência, Florianópolis, v. 31, n. 59, p. 6-7. Disponível em: encurtador.com.br/tOVY5. Acesso em: 20 maio 2020.

${ }^{39}$ JIKINGS, Ivana. Apresentação. In: MÉSZÁROS, Istivan. Para além do capital. São Paulo: Boitempo, 2008 , p. 13.

${ }^{40}$ EVANGELISTA; SOUZA, op. cit.

${ }^{41}$ EVANGEISTA, Olinda; SEKI, Allan K.; SOUZA, Arthur Gomes; TITON, Mauro; AVILA, Astrid B. (org.). Desventuras dos professores na formação para o capital. Campinas: Mercado das Letras, 2019, p. 7-9.

${ }^{42}$ LAVAL, Christian. A escola não é uma empresa: o neoliberalismo em ataque ao ensino público. São Paulo: Boitempo, 2019, p. 17. 
A maior tragédia, porém, vislumbra-se durante a quarentema da Covid-19. Aproveitando-se da catástrofe humanitária da pandemia, o governo Bolsonaro procura justificar as profundas mudanças que pretende impor à rede pública de ensino. É por esse motivo que a quarentena tem sido designada, eufemisticamente, de 'período de transição' para o modelo de ensino remoto - ou aprendizagem virtual, tecnológica, digital ou mesmo educação a distância (EAD) -, fato este que passaria a ser regra na Educação Básica. É por essa razão que os chamados aparelhos privados de hegemonia (OCDE, Unesco, Banco Mundial e outros) vêm sugerindo aos países em quarentena seus marcos legais, para que as alterações possam ser 'operacionalizadas' imediatamente e possibilitem a permanência desses novos aparatos do capitalismo digital nas práticas educativas desses países. Para isso, é importante, segundo essas instituições de consenso, que as orientações abranjam um amplo conjunto de flexibilizações: dos currículos, da avaliação, dos métodos de ensino, da jornada letiva, das certificações e dos materiais didáticos. Na verdade, o que está em pauta é a defesa da tese de que os professores são incapazes de lidar com a situação, o que resulta na proposta de reconversão docente via formação contínua, 'ágil e efetiva', tendo em vista superar a alegada deficiência. Além disso, a formação de gestores e familiares também está no horizonte, seja porque é preciso uma liderança competente, seja porque os pais teriam necessariamente de se transformar em "auxiliares de ensino" ${ }^{43}$

E não somente durante a pandemia, mas especialmente após. Isso tem acontecido porque muitos professores foram obrigados a continuar suas aulas online, à moda do ensino remoto, à moda do EAD, como reza a lógica do chamado 'capitalismo digital'. Muitos professores se queixam das dificuldades desse tipo aula, e os pais também, porque tiveram que dispender de tempo para ajudar seus filhos nas tarefas de casa exigidas pela escola. Pois bem, corremos o risco de que a formação de professores, daqui por diante, ocorra na modalidade EAD, fato este que aceleraria a apropriação, por parte do mercado, dos cursos de formação de professores. Um outro objetivo por trás do fetiche do ensino à distância poderia ser a desvalorização do papel dos professores na educação presencial, a fim de estimular os pais a aderir ao chamado homeschooling, que ganhou novo folego durante o isolamento social do coronavírus, reacendendo as ideias do Ministério da Educação. Tudo isso tem sentido, porque está em jogo a possibilidade de a pandemia servir como 'janela' para precarizar ainda mais a educação pública. ${ }^{44}$

Isso posto, urge perguntar: o que será que está por trás da exigência de desenvolver o ensino remoto durante a pandemia? O que se tem, já faz um certo tempo, são grande Institutos e Fundações, que estão cada vez mais imiscuídos no MEC, por meio de um grupo denominado 'Todos pela Educação'. Este grupo, de maneira expressiva, busca determinar as ações do governo e promover legislações de seu próprio interesse. Moral da história: muitas destas instituições - entre as quais institutos sociais articulados a grandes bancos (privados) e fundações (nacionais e internacionais) insistem em interferir na gestão do MEC e do Conselho Nacional de Educação (CNE), órgão regulador que dá sustentação para ações e determinações legais, através de Pareceres, Regulamentos, Decretos, Medidas Provisórias, Projetos de Lei e tudo o mais que tramite neste âmbito. ${ }^{45}$

\section{A Educação Física durante a pandemia do cononavírus: experiências e desafios}

Durante a pandemia, como estavam acostumados a se exercitar nas escolas, clubes e academias, é natural que crianças, jovens, adultos e velhos tenham sentido os impactos do isolamento social. Também podemos perceber como houve mobilização, por parte do Colégio Brasileiro de

\footnotetext{
${ }^{43}$ EVANGELISTA; SOUZA, 2020.

${ }^{44}$ EVANGELISTA; SOUZA, 2020.

${ }^{45}$ AUGUSTO; SANTOS, 2020, p. 257.
} 
Ciências do Esporte CBCE) ${ }^{46}$ e de seus treze Grupos de Trabalhos Temáticos (GTT), para fazer reflexões em lives, divulgar notas no site da entidade e até vídeos com sugestões de práticas corporais para serem feitas em casa. Assim, por meio da sua Direção Nacional, o CBCE vem propondo um processo comunicativo de reflexões e esclarecimentos sobre as práticas corporais em tempos de distanciamento social e coronavírus. Nessas reflexões, assim como nas notas desses grupos, há questões de caráter universal, que atingem a educação (por exemplo, EAD, formação de professores, etc.) e as outras áreas do conhecimento, como veremos mais adiante, mas articuladas às questões de caráter específico da Educação Física (a Educação Física escolar, a Pedagogia do Esporte, a importância dos jogos e brincadeiras adaptados a pequenos espaços da casa, a questão do lazer, reflexões sobre o corpo e a ginástica, entre outras práticas). Nas notas dos diversos GTTs, é possível constatar uma preocupação em seguir as orientações e os protocolos da Organização Mundial da Saúde (OMS). O mote de reflexão para a comunidade acadêmica e escolar tem sido a Covid-19 e, consecutivamente, a importância do isolamento social e das práticas corporais realizadas com segurança, em observância às determinações científicas internacionais. Assim, o lema é: "fiquem em casa!", para preservar vidas e manter o corpo em movimento com práticas corporais individuais e coletivas. Fica claro, nas posições do CBCE, que o mais importante é a saúde e a vida dos seres humanos, e não a economia política do neoliberalismo destrutivo e letal. Alguns estudiosos, além de defenderem a quarentena, sugeriram práticas da cultura corporal, com seus jogos, ginásticas, danças e esportes adaptados aos espaços de moradia; bem como a leitura de pesquisas produzidas no interior do CBCE e de clássicos sobre as problemáticas do corpo, da ginástica, do lazer e do esporte, entre outros conteúdos culturais.

Pois bem, na contramão da ciência, fomos surpreendidos, mais uma vez, pelo necroliberalismo de Bolsonaro, com sua sanha lúgubre e macabra, que, como sabemos, pensa mais na economia do que na saúde e nas vidas dos trabalhadores. Mais uma vez, ele surgiu no 'chiqueirinho' do Planalto, para decretar Medidas Provisórias e Projetos de Lei com o intuito de acabar com o isolamento social e, com isso, aumentar o número de mortes pela Covid-19. Maior número de mortes, para ele, é uma vitória, pois assim restarão poucos velhos e pobres para requerer uma outra previdência como a atual. Movido por esse intuito nefasto, Bolsonaro publicou um decreto ampliando os serviços considerados essenciais, que, segundo ele, não podem ser fechados durante a pandemia do novo coronavírus.

O Decreto $\mathrm{n}^{\circ} 10.344$, de 11 de maio de 2020, incluiu academias, salões de beleza e barbearias no rol de serviços essenciais, sob a justificativa de que esses estabelecimentos têm relação direta com a saúde e a higiene. Bolsonaro voltou a defender a ideia de que "saúde é vida" e a apregoar que "se a pessoa fica em casa sedentária, aumenta o colesterol, piora a saúde". Ao baixar esse Decreto, teve a intenção de confundir os brasileiros, pois a abertura das academias em momento de expansão acelerada do novo coronavírus é medida temerária. Além disso, contraria a orientação do novo 'exMinistro' da Saúde (Teich), que defende, a exemplo do seu antecessor, Mandetta, a quarentena e o lockdown. Todavia, na prática, o Decreto não permite a liberação automática de serviços e atividades, pois estados e municípios têm o poder de estabelecer suas próprias políticas de saúde - inclusive a quarentena - e de classificar os serviços essenciais nas suas esferas de competência, conforme definiu o Supremo Tribunal Federal (STF) em abril.

O Decreto $n^{\circ} 10.344 / 2020$ dividiu opiniões entre os profissionais de Educação Física. Alguns especialistas destacaram que os exercícios físicos são fundamentais para a manutenção da saúde, mas não deixaram de frisar, por outro lado, que os estabelecimentos esportivos podem ser vetores de contaminação do novo coronavírus. Outros recomendaram a observância integral das medidas de proteção sugeridas pela ciência como condição para a liberação, muito embora não tenham descartado o risco de infecção. Em síntese, por ora, o ambiente de academia não é o ideal para a prática de

${ }^{46}$ Cf.: www.cbce.org.br. 
atividades físicas. Talvez seja melhor desenvolver as práticas corporais ao ar livre ou em casa, locais mais seguros, tanto para o indivíduo quanto para a coletividade.

Todavia, o referido Decreto não teve eco nos estados. A opção de Bolsonaro sempre foi, desde sempre, salvar a economia, e não as vidas, com o único fim de agradar aos apoiadores empresários e aos fascistas fanáticos. A maioria dos estados decidiu não acatar a ordem do mandatário do executivo, à exceção do Rio Grande do Sul, de Pernambuco e de Santa Catarina, cujo governador, o bombeiro e advogado Carlos Moisés, filiado ao PSL, duas semanas antes, já havia antecipado a cruel, ridícula e irresponsável reabertura das academias no estado. Antes mesmo da 'ideia de jerico' de Bolsonaro, já havia escancarado as portas das academias, dos salões de beleza, de shopping centers e de outros estabelecimentos, considerados 'essenciais'. Vale destacar que foi o próprio governador que solicitou a abertura ao Cref 3 (Conselho Regional de Educação Física de Santa Catarina).

Esses estados emitiram uma nota técnica para permitir a retomada das atividades das academias, com medidas e protocolos de segurança para usuários e funcionários. Na página do Conselho Federal de Educação Física (Confef), não encontramos nenhuma orientação, mas sim na do Cref 12 (Pernambuco) ${ }^{47}$ que antes mesmo do Decreto já havia editado medidas sanitárias para quando fosse autorizada a reabertura das academias. Vale ressaltar, no entanto, que o Confef encaminhou um ofício ao presidente, no qual dizia:

O Confef, ao tempo em que cumprimenta Vossa Excelência, manifesta agradecimento pela iniciativa de inserir as "academias de esporte de todas as atividades essenciais definidas no Decreto $\mathrm{n}^{\circ}$ 10.344, de 11 dede maio de 2020" [...]. Com essa atitude, Vossa Excelência reafirmou que o valor da atividade física, praticada de forma regular, sistemática e orientada por Profissionais de Educação Física, agrega à saúde da população brasileira em termos de prevenção de doenças, promoção da saúde e desenvolvimento humano, atendendo às recomendações de biossegurança. ${ }^{48}$

Moral da história: com essa demonstração de proselitismos e politicagem por parte do Confef, temos a oportunidade de intensificar as críticas acumuladas pelo Movimento Nacional Contra a Regulamentação do Profissional de Educação Física (MNCR).

No que refere à Educação Física escolar, houve uma intensa mobilização, que culminou com um belo debate sobre os desafios da Educação Física nas escolas e as chamadas TDICs (Tecnologias Digitais de Informação e Comunicação) durante a quarentena da Covid-19. O debate foi realizado com a participação da Dr. ${ }^{a}$ Paula Bianchi, professora da Unipampa - Campus de Jaguarão, docente do Programa de Pós-Graduação em Educação, pesquisadora do LaboMídia e integrante do GTT Mídia e Comunicação do Conbrace/CBCE, além do Dr. Paulo Carrano, da Universidade Federal Fluminense (UFF).

A professora Paula posicionou-se $\operatorname{assim}^{49}$ :

A pandemia causada pela Covid-19 provocou a suspensão das aulas em todos os níveis de ensino, nas redes pública e privada. Desde então, muito se tem falado do uso das TDICs no ensino e na aprendizagem como uma forma de diminuir os prejuízos aos estudantes e mantê-los mais próximos da escola e das atividades escolares durante esse período. Se, por um lado, as plataformas

\footnotetext{
${ }^{47}$ Cf.: www.cref12.org.br.

${ }^{48}$ Cf.: http://www.confef.org.br/.

${ }^{49}$ Este texto fornecido pela própria autora representa uma síntese das reflexões da prof. ${ }^{\text {a Paula Bianchi durante a }}$ referida live da Secretaria do CBCE do Rio de Janeiro (27/abril/2020), com o título: os desafios da Educação Física escolar na pandemia da Covid-19.
} 
educacionais digitais e as aulas a distância são mais conhecidas e difundidas no Ensino Superior, considerando-se que muitas instituições universitárias dispõem de infraestrutura tecnológica e suporte técnico para o desenvolvimento de atividades mediadas pelas tecnologias, e a legislação educacional brasileira regulamenta a oferta da educação a distância nos cursos de graduação e de pós-graduação em todo o país. Por outro, na Educação Básica, a presença e o emprego das TDICs nos processos educativos ainda não é uma unanimidade nas escolas brasileiras, e a implementação das aulas a distância esbarra na falta de previsão e orientação legal, já que não está prevista na Lei de Diretrizes e Bases da Educação Nacional (LDBEN - Lei $n^{\circ}$ 9.394/1996). Mesmo assim, conhecendo a fragilidade das instituições educativas em oferecer atividades mediadas pelas tecnologias, especialmente as escolas públicas, o CNE, em abril de 2020, indicou a utilização da modalidade EAD como alternativa para a reposição de aulas, baseado no Decreto-Lei $n^{\circ} 1.044$, de 21 de outubro de 1969. Infelizmente, medidas como essa servem apenas para acentuar as desigualdades de acesso e permanência dos estudantes na educação.

Faz algum tempo que nos dedicamos ao estudo das questões envolvendo a Educação Física e as TDICs, especialmente na formação inicial e continuada de professores da área. Juntamente com colegas do LaboMídia da UFSC, procuramos pensar e agir para a integração das TDICs à Educação Física escolar. Entretanto, falar em integração significa muito mais do que a simples utilização de ferramentas tecnológicas por parte de docentes e estudantes. Trata-se de um processo complexo, que requer, entre tantos aspectos, políticas públicas educacionais que garantam o acesso (em quantidade e qualidade) às ferramentas tecnológicas, tanto aos docentes quanto aos estudantes, dentro e fora da escola; infraestrutura adequada, suporte técnico e manutenção permanente de equipamentos $e$ redes para uso pedagógico de tecnologias nas instituições educacionais; currículos escolares que dialoguem criticamente com os elementos da cultura digital; e formação inicial e continuada de professores na perspectiva das TDICs, mas que não se detenha apenas na preparação técnica desses profissionais.

Com base nisso, refletindo sobre as experiências recentes com atividades remotas/não presenciais, acreditamos que uma das possiveis consequências dessa "EAD de ocasião" (como bem caracterizou o Prof. Giovani De Lorenzi Pires) é justamente estigmatizar o que entendemos ser uma excelente possibilidade para pensar e praticar a integração das tecnologias aos processos educacionais. Além disso, no caso da Educação Física escolar, em que ainda são poucas as experiências pedagógicas com as TDICs, corre-se o risco de que, a partir de 'aulas online' baseadas na perspectiva do corpo biológico e do exercício físico, a disciplina volte a ser entendida como mera atividade compensatória do esforço intelectual do estudante ou como passatempo.

Em uma consulta informal a alguns professores de Educação Física de escolas públicas do Rio Grande do Sul sobre como as atividades não presenciais estavam ocorrendo, ficamos sabendo que o conteúdo da disciplina é preparado pelo professor desde sua casa, com materiais didáticos e recursos tecnológicos pessoais, depois enviado para os estudantes através de grupos de WhatsApp. O material, quase sempre, está organizado em duas partes: uma teórica (texto elou vídeos caseiros ou da internet) e a outra prática (com indicação de exercícios físicos e jogos). É importante destacar que esse processo está sendo chamado de 'atividade programada pelo profissional', pois não é seguro afirmar que poderá ser computado como aulas.

Por fim, diante do exposto, tentamos elencar alguns aspectos decorrentes deste momento: I) a EAD de ocasião revelou-se uma abordagem legalista e conteudista, longe de ser formativa $e$ qualificada; II) a sobrecarga de trabalho docente é aprofundada pelas novas tarefas do professor em tempos de coronavírus, pois precisa preparar atividades na modalidade não presencial, para a qual não tem formação adequada, com equipamentos e rede disponíveis em sua casa, além de agir como ator diante das câmeras e se ocupar dos meios para a circulação do conteúdo, fazendo com que chegue à maioria dos estudantes); III) a brecha digital (abismo digital/desigualdade digital) existe e atinge uma grande parcela da população brasileira, entre estudantes e professores; IV) os 
mercadores da educação vão aproveitar não só esse momento mas também 'futuras pandemias' para vender EAD (ou melhor, vender ferramentas tecnológicas) a todo custo; V) o cenário atual mostra que estamos certos (pesquisadores da área) em defender que cada professor deve ser formado para pensar e agir como um mídia-educador, de modo que a educação midiática na escola não seja responsabilidade unicamente de um professor especialista. Momentos como este mostram a importância da mídia-educação ${ }^{50}$ na formação de professores de todas as áreas do conhecimento.

$$
* * *
$$

Dando continuidade, faremos algumas anotações pontuais sobre outra problemática social e política debatida na academia e em movimentos sociais e sindicais, quando estão em pauta a seguridade social e a reforma trabalhista. Nosso objetivo é iniciar o debate sobre a devastação da velhice na sociedade capitalista, motivados pela perda do nosso saudoso e grande ator Flávio Migliaccio, que se suicidou aos 86 anos, deixando na sua carta de despedida a seguinte mensagem: "Me desculpem, mas não deu mais. A velhice neste país é o caos, como tudo agora. A humanidade não deu certo. Eu tive a impressão de que foram 85 anos jogados fora num país como este. E com este tipo de gente que acabei encontrando. Cuidem das crianças de hoje!’. Essas pungentes palavras nos levam a pensar nos milhões de velhos e velhas do país, alertando-nos não só para o modo como são tratados diuturnamente, diante de toda essa 'velhofobia' capitalista, mas principalmente durante a pandemia. Suas palavras são um alerta, um apelo, uma súplica, um documento histórico de caráter político. Para Migliaccio, a velhice no Brasil é "um caos". As mensagens dele, aliadas a outras posições eugênicas e preconceituosas do atual presidente durante a pandemia da Covid-19, expuseram, de maneira inequívoca, os maus-tratos das políticas públicas e sociais, que trazem em seus enunciados e práticas a perspectiva da velhice-estorvo do necrocapitalismo.

A ideia é, a partir desta edição, começar a desconstruir estereótipos e preconceitos, além de problematizar a construção da velhice e as contradições forjadas pela lógica do capital. Além do mais, trata-se, fundamentalmente, de buscar novos papéis para trabalhadores e trabalhadoras idosos e, obviamente, redimensionar seus efetivos direitos, destruídos pelas políticas neoliberais na sociedade do "deus mercado", no Brasil e em grande parte dos países todo mundo. O envelhecimento é concebido como 'sobrevida', um termo técnico do jargão atual que mal disfarça sua sinistralidade. Nesse sentido, o envelhecimento, que em certa medida deveria significar melhoria das condições de vida de quem já foi suficientemente sugado pelo capital, agora é tratado como motivo para dificultar o acesso ou reduzir os valores dos benefícios previdenciários. Na verdade, trata-se de uma punição pela tal sobrevida, punição que atinge principalmente os mais pobres, que, para os neoliberais, cometeram o crime de sobreviver aos 65 anos estipulados pelo IBGE (e pelas normas internacionais) para caracterizar o idoso. ${ }^{51}$

Outro ponto que ficará pendente neste editorial é a reflexão sobre a pós-pandemia. A ideia é lançar uma pergunta, baseada na música de Milton Nascimento Nada será como antes, qual seja: como sairemos desta tríplice crise do capital (econômica, política e sanitária)? Sairemos dessa

${ }^{50}$ BELLONI, Maria Luiza. O que é mídia-educação: polêmicas do nosso tempo. 2. ed. Campinas: Autores Asociados, 2005;

FANTIN, Monica. Mídia-educação: conceitos, experiências, diálogos Brasil-Itália. Florianópolis: Cidade Futura, 2006.

${ }^{51}$ VIANA, Maria C. W. Reforma da Previdência: contexto atual, pós-verdade e catástrofe. Futuros do Brasil: Textos para debate, Rio de Janeiro, n. 4, p. 1-19, maio. 2017. Disponível em: encurtador.com.br/puCQY. Acesso em: 20 maio 2020. 
pandemia mais fortalecidos, solidários e com mais consciência política de classe em tempos em que se acirram as contradições do capital?

$\mathrm{Na}$ nossa maneira de analisar, pode ser um tempo único para avaliar valores e atitudes individuais e coletivos, questões objetivas e subjetivas. Nessa dimensão, a música Nada será como antes pode ser vista, essencialmente, como oportunidade, como temos visto, para apontar as mazelas do capitalismo concentrador de riquezas nas mãos de alguns bilionários, enquanto a desigualdade social escancarou-se com a Covid-19 e passou a semear óbitos nas periferias empobrecidas das cidades e na zona rural, onde a maioria da população padece de fome, em meio a moradias insalubres, desemprego, subemprego e doenças diversas. Pensando dessa forma, somos da opinião de que o tempo de quarentena não é pura e simplesmente um tempo de filantropia e doação de comida e remédio para os nossos iguais. A nosso ver, é também um tempo de desconstrução do que havia 'antes', tempo de subverter a lógica e os valores do capital - desde sempre, mas em especial durante a quarentena -, tendo como princípio de formação humana uma nova perspectiva da consciência política e de classe.

$* * * * *$

Essa edição expressa mais um esforço coletivo da nossa comissão editorial, no sentido de veicular todos os textos submetidos no ano de 2019 e que se encontravam aprovados em nosso acervo desde então. Trata-se, pois, a exemplo do anterior, de um fascículo com um grande número de artigos originais e de textos da seção Porta Aberta, o que exigiu dos colaboradores da revista e do pessoal do Portal de Periódicos da BU/UFSC um intenso e cuidadoso trabalho de preparação dos manuscritos e revisão de metadados, de modo a garantir mais um número com a qualidade técnica que marca a revista Motrivivência.

Por meio do conjunto de 36 textos que publicamos nessa edição, distribuídos nas duas seções, acreditamos estar oferecendo uma generosa contribuição à nossa comunidade acadêmica, com artigos que abordam amplo e variado leque de temas afetos ao nosso campo do conhecimento, com abordagens teórico-metodológicas relevantes e inovadoras, que demonstram o estado do conhecimento no âmbito da Educação Física, esporte e lazer.

Na seção de Homenagens, destacamos as inestimáveis contribuições da profa. Bianca Natália Poffo, a Bia, colaboradora da Motrivivência há exatos 10 anos e atualmente coordenadora da nossa comissão editorial. Para homenageá-la, pedimos depoimentos da professora Fernanda Fauth, sua colega desde a graduação, e dos editores da revista, profs. Mauricio e Giovani. Bia é, sem dúvida, merecedora de todas essas homenagens.

Na capa dessa edição, em consonância com o espírito desses nossos tempos e com as críticas promovidas nesse editorial, trazemos uma imagem bastante significativa. Trata-se de imagem do monumento Tortura Nunca Mais, criado pela Prefeitura Municipal do Recife/PE para homenagear os torturados, mortos e desaparecidos da ditadura militar que decorreu do golpe militar de 1964 no Brasil. Concebido pelo arquiteto piauiense Demétrio Albuquerque, foi inaugurado em agosto de 1993. Postado às margens do rio Capibaribe, na praça Padre Henrique, ele próprio sequestrado, torturado e assassinado pela ditadura, o monumento representa um artefato de tortura usado pelos militares chamado "pau-de-arara", para que nunca seja esquecido e que nunca mais se repitam essas atrocidades aos direitos humanos ${ }^{52}$.

\footnotetext{
${ }^{52}$ Foto de capa disponível em https://oreversodomundo.com/2016/05/26/tortura-nunca-mais/ Créditos da foto: Leonardo Chaves
} 
Aproveitamos esse editorial ainda para justificar a decisão tomada pela comissão editorial no sentido de suspender as submissões a partir do dia 01 de junho. Essa ação visa justamente garantir que nossa boa qualidade editorial continue sendo observada, em respeito aos autores que nos confiam a sua produção acadêmica. Ocorre que, provavelmente em decorrência do isolamento social determinado pela pandemia da COVID-19, nós observamos um aumento inesperado e de grandes proporções no número de submissões, nos meses de abril e maio. Isso faz com que os nossos editores de seção estejam sobrecarregados no acompanhamento de textos designados e em avaliação, assim como praticamente levou ao esgotamento da disponibilidade de nossos avaliadores permanentes e $a d$ hoc. É nossa intenção reabrir as submissões tão logo essa sobrecarga esteja equacionada e que possamos voltar a acolher novas contribuições para editoração com a segurança e a celeridade que caracterizam o trabalho do nosso periódico.

Finalmente, esperamos que os excelentes artigos publicados nesta edição possam trazer não apenas profícuas reflexões para a Educação e a Educação Física mas também elementos teóricometodológicos e político-pedagógicos para que possamos enfrentar essa quarentena e sair desse processo acumulando novos avanços para a ciência, como novas vacinas, por exemplo, de braços dados com uma saúde pública e coletiva, a fim de exterminar a Covid-19 do nosso convívio social. Consideramos importante, neste momento de crise, encarar o desafio de criar a unidade de esquerda com todos os trabalhadores e trabalhadoras, com movimentos sociais e sindicais, nesse clima mórbido de perdas de vidas pela Covid-19 e de mal-estar com a lógica do capital, que, com a sua democracia liberal e burguesa, vem exterminando nossos presente e futuro.

Em tempos de degradação da economia política, ambiental, sanitária ética e estética, mandamos um recado para Bolsonaro e sua trupe de fascistas, que celebram, como já evocamos nestas páginas, as notícias do aumento do número de óbitos de mais de vinte mil corpos: "Quem cala sobre teu corpo, consente na tua morte, talhada a ferro e fogo nas profundezas do corte". 53

Mais um outro recado aos que querem a volta da ditadura e não se sensibilizaram com as letras das canções $O$ bêbado e a equilibrista e Querelas do Brasil: escutem um reforço de Zé Ramalho, em Temporal:

Quem viu os cachorros negros

Latindo para o luar

E o voo vão dos morcegos

Gritando mudos no ar

Conhece a força guardada

Na mola dos temporais

Escurecendo as estrelas

Nos ombros dos generais.

Por fim, desejamos uma leitura crítica e propositiva desta edição.

${ }^{53}$ Trecho da música Menino, de Milton Nascimento. 
Florianópolis, outono de 2020.

Maurício Roberto da Silva, Giovani De Lorenzi Pires, Rogério Santos Pereira

Editores

Paula Bianchi

Editora Associada nesta edição

FORA, BOLSONARO!

DITADURA, NUNCA MAIS! TORTURA, NUNCA MAIS! CENSURA, NUNCA MAIS! VIVA A ARTE E A CULTURA LIVRES!

VIVA ALDIR BLANC! MARIELLE PRESENTE! 